\title{
PROMOÇÃO DA SAÚDE: UM NOVO OLHAR AO PACIENTE COM TRANSTORNO MENTAL
}

Giseli Orben

Acadêmica do Curso de Enfermagem, Centro Universitário Barriga Verde, gisele_riof@hotmail.com

Lucas Corrêa Preis

Acadêmico do Curso de Enfermagem, Centro Universitário Barriga Verde,

lucaspreis@yahoo.com

Kassiane Dutra

Acadêmica do Curso de Enfermagem, Centro Universitário Barriga Verde, kassidutra@hotmail.com

Jaqueline Caetano

Acadêmica do Curso de Enfermagem, Centro Universitário Barriga Verde, jaqueline-gr@hotmail.com

Greice Lessa

Doutoranda em Enfermagem, Universidade Federal de Santa Catarina, greicelessa@hotmail.com Mislene Beza Gordo Sarzana Acadêmica do Curso de Enfermagem, Centro Universitário Barriga Verde, misbn@hotmail.com

\section{RESUMO}

O modelo hospitalocêntrico é caracterizado pela superlotação dos manicômios, visto que esses eram considerados como campo de concentração, devido às condiçôes precárias de assistência, com abordagem terapêutica pautada em 
isolamento familiar e social, violência e desrespeito ao paciente com transtorno mental, que era tratado como "louco", violando, assim, os direitos do ser humano (BORBA et al., 2012). A reforma psiquiátrica no Brasil é um processo histórico, com o objetivo de substituir o modelo hospitalocêntrico por serviços de caráter substitutivo, como: redes de atenção à saúde mental, Centro de Atenção Psicossocial (CAPS), dentre outros, a fim de humanizar o atendimento ao paciente psiquiátrico, visando ao resgate da cidadania e proporcionando a reabilitação psicossocial do paciente com transtorno mental (CARARRA et al., 2015). No ano de 1987, por meio do II Congresso Nacional de Trabalhadores da Saúde Mental, ficou estabelecido o dia 18 de maio como Dia Nacional da Luta Antimanicomial, propondo uma mudança de cenário nacional que favoreça e proteja os direitos dos usuários e familiares a uma atenção digna nos serviços de saúde, buscando alternativas de tratamento à sociedade na qual o paciente portador de transtorno mental está inserido (BARBOSA; COSTA; MORENO; 2012). Com base nisso, desenvolveu-se o projeto intitulado "Nossos Delírios: uma Reflexão sobre a Loucura Humana", representando uma adesão ao movimento da luta antimanicomial, a fim de conscientizar os acadêmicos e a população em geral de que os portadores de transtornos mentais devem ser tratados de forma humanizada, com a participação da família e sem utilização do modelo baseado na internação em manicômios, onde a forma de tratamento era pautada na violência, desumanização e exclusão social da pessoa humana. O projeto desenvolvido integrou os Cursos de Enfermagem e de Psicologia, do Centro Universitário Barriga Verde (UNIBAVE), representando os cursos que mais se aproximam da temática em seus campos de trabalho. As atividades foram desenvolvidas em sala de aula, nas disciplinas de Enfermagem em Saúde Mental II e a História da Psicologia, dos Cursos de Enfermagem e Psicologia, respectivamente, coordenados pelos professores responsáveis das disciplinas e demais profissionais da instituição. A atividade desenvolvida proporcionou a conscientização da população em geral e acadêmica, por meio da reconstrução da história da saúde mental, utilizando para isso obras de arte, cenários, esculturas, fotografias e objetos que representavam os diferentes tipos de tratamentos destinados aos pacientes psiquiátricos e atividades sobre a história do sofrimento psíquico, bem como o tratamento ao 
paciente psiquiátrico antes e após a reforma psiquiátrica. Além disso, visando ao desenvolvimento de um espaço de debate e de troca de conhecimentos entre profissionais e acadêmicos, foi realizada também uma mesa redonda com o tema "Saúde mental", contando com a participação de instituiçôes de ensino e de saúde da região, além de representantes do CAPS e outros profissionais da área da saúde. A partir do movimento da luta antimanicomial, estabeleceu-se que o dia 18 de maio seria o Dia Nacional da Luta Antimanicomial, assumindo efetivamente a utopia por uma sociedade sem manicômios, marcando uma ligação entre profissionais e sociedade, a fim de possam enfrentar a questão da loucura e suas formas de tratamento, pautada enquanto movimento social e sindical. (BARBOSA; COSTA; MORENO; 2012). Com a Reforma Psiquiátrica, vieram as mudanças nos modelos de atenção à saúde mental, que vão além da implantação e ampliação das redes de serviços, mas assistência ao paciente com sofrimento psíquico, exigindo flexibilidade nas açóes e alteraçóes individuais e coletivas de todos os envolvidos nesse processo, com um único fim: o bem-estar desse paciente (RIBEIRO, 2015). Surge a substituição progressiva dos hospitais psiquiátricos tradicionais por serviços abertos de tratamento, como a rede de atenção à saúde mental, que inclui a atenção básica, os Centros de Atenção Psicossocial, os serviços especializados, os ambulatórios de saúde mental, o hospital dia, os serviços de urgências e emergências psiquiátricas e os serviços de residências terapêuticas, com o objetivo de direcionar novas formas de cuidar em saúde mental, com assistência humanizada, possibilitando a participação do paciente e familiar no seu processo de tratamento e reinserção social (CARARRA et al., 2015). É relevante a participação de uma equipe multiprofissional engajada no desenvolvimento de açóes e atenção psicossocial, voltadas à escuta, ao acolhimento e à confiança, a fim de estabelecer vínculos entre profissionais, pacientes e familiares, favorecendo um tratamento com ênfase na reabilitação e reinserção social, proporcionando uma melhor qualidade de vida. Neste sentido, os cursos de graduação da área da saúde devem constantemente relacionar a teoria com a prática, em suas disciplinas, favorecendo ao acadêmico uma nova visão a respeito da saúde mental, pautada em novas estratégias de cuidar, além de habilidades técnicas, desenvoltura para lidar com as relaçóes humanas e as ressocializaçóes dos portadores de transtornos 
mentais na família ou na comunidade (SILVA et al., 2013). Os paradigmas da reforma psiquiátrica são sustentados por conferências, documentos e portarias, que apontam a substituição progressiva do hospital psiquiátrico por uma rede de atenção integral à saúde mental antimanicomial, com o intuito de resgatar a cidadania, visando à desinstitucionalização da psiquiatria. Compreende-se que, após a reforma psiquiátrica, buscaram-se estratégias para inovar a forma de cuidar em saúde mental, requerendo dos profissionais que atuam na área capacitação para acolher e escutar, tornando-se capazes de compreender a realidade da família e da pessoa com transtorno mental. O projeto realizado permitiu repassar à população acadêmica e à sociedade em geral a trajetória e os avanços da reforma psiquiátrica, com ênfase na conscientização sobre os serviços de saúde mental, atualmente com uma nova visão e abordagem às pessoas com sofrimento psíquico.

Palavras-chave: Saúde Mental; Serviços de Saúde Mental; Enfermagem; Psicologia.

\section{REFERÊNCIAS}

BARBOSA, G. C.; COSTA, T. G.; MORENO, V. Movimento da luta antimanicomial: trajetória, avanços e desafios. Cadernos Brasileiros de Saúde Mental, Florianópolis, v.4, n.8, p.45-50, 2012.

CARRARA; G. L. R. et al. Assistência de enfermagem humanizada em saúde mental: uma revisão da literatura. Revista Fafibe On-Line, Bebedouro, v.8, n.1, p.86-107, 2015.

BORBA, L. et al. Assistência em saúde mental sustentada no modelo psicossocial: narrativas de familiares e pessoas com transtorno mental. Revista da Escola de Enfermagem da USP, São Paulo, v.46, n.6, p.1406-1414, 2012.

RIBEIRO, M. C. Trabalhadores dos Centros de Atenção Psicossocial de Alagoas, Brasil: interstícios de uma nova prática. Interface: Comunicaçáo, Saúde e Educação, São Paulo, v.19, n.52, p.95-107, 2015. 
SILVA, N. S. et al. Percepção de enfermeiros sobre aspectos facilitadores e dificultadores de sua prática nos serviços de saúde mental. Revista Brasileira de Enfermagem, Brasília, v.66, n.5, p.745-52, 2013. 